\title{
Assessment of the Challenges Faced and Support System of the Clients with Endocrinal Disorder Attending Endocrine OPD, in a Selected Hospital in Kolkata
}

\author{
Soma Chatterjee ${ }^{1}$, Uma Rani Adhikari, ${ }^{2, *}$ \\ ${ }^{1}$ Priyamvada Birla Institute of Nursing, Kolkata-700156, India. \\ ${ }^{2}$ College of Nursing, Medical College \& Hospital, Kolkata-700073, India.
}

\begin{abstract}
How to cite this paper: Soma Chatterjee, Uma Rani Adhikari. (2021) Assessment of the Challenges Faced and Support System of the Clients with Endocrinal Disorder Attending Endocrine OPD, in a Selected Hospital in Kolkata. International Journal of Clinical and Experimental Medicine Research, 5(2), 192-201. DOI: 10.26855/ijcemr.2021.04.013
\end{abstract}

Received: March 5, 2021

Accepted: March 30, 2021

Published: April 19, 2021

*Corresponding author: Uma Rani Adhikari, College of Nursing, Medical College \& Hospital, Kolkata-700073, India.

Email: w2uma@yahoo.com

\begin{abstract}
Background: Nowadays, endocrinal disorder is increasing day by day. It has impacts on physical, psychological, personal, social and financial wellbeing of people. So the study was undertaken to identify the challenges and support system of client with endocrinal disorders. Methods: Total 170 clients with diabetes, thyroid and pituitary disorders were included as study sample by using purposive sampling technique between October and November, 2019. The researcher collected demographic data by administering structured interview schedule and data regarding challenges they face and the support system they receive by administering semi structured interview schedule. Validity and reliability of the tool was established before final data collection. The collected data were analyzed both by using descriptive and inferential statistics. Result: Study showed that psychological challenges mean percentage $68.25 \%$ which ranked $1^{\text {st }}$ among all the domain of challenges and they get maximum support from their family members although social support is comparatively less. All the clients have some challenges in each domain. There is also a significant association found between overall challenges with gender, age, marital status, education, occupation, number of family member, types of endocrinal disorder and duration of suffering. Conclusions: The study revealed that due to chronic suffering they are getting more challenges in psychological domain. They receive support from their family and social members but social support is very less for them. So, it is very important for health care workers including nurses to assess those challenges and counsel the client to overcome those as much as possible.
\end{abstract}

\section{Keywords}

Endocrinal Disorders, Challenges, Support System

\section{Introduction}

Developing countries do not pay enough attention to the clients with endocrinal disorder regarding their symptoms, the challenges they face throughout the life in different aspects of life thus resulting increased morbidity and mortality rate [1]. In 2000, India (31.7 million) topped with the highest 3rd number of people with diabetes mellitus followed by China and the United States among the world [2]. In India, there are more than 62 million diabetic in- 
dividuals who are currently diagnosed with the disease. In 2000, India (31.7 million) topped with the highest $3^{\text {rd }}$ number of people with diabetes mellitus followed by China and the United States among the world [3]. There is also a significant burden of thyroid diseases. It has been reported that in India about 42 million people suffer from thyroid disorders [4].

A qualitative focus group study is conducted by Trief M. Paula, Sandberg G. Jonathan, Dimmock J. A. et al. [5] on Personal and Relationship Challenges of Adults with Type 1 Diabetes and it is seen that they face behavioral, emotional, and interpersonal challenges. In India, Primary hyperparathyroidism (PHPT) unlike in the Western world, is largely asymptomatic disease due to lack of awareness [6]. According to Walker, M. D., Rubin, M. and Silverberg, S. J. [7], many patients with mild PHPT report nonspecific symptoms, including weakness, easy fatigability, memory loss, decreased concentration, irritability, loss of initiative, anxiety, and sleep disturbance. Clients with thyroid disorder face many difficulties like excessive fatigue, depression, hair loss, unexplained weight gain, constipation, sleep problems, mental fogginess and anxiety [8]. Psychiatric disturbances are very frequently observed with thyroid disorders.

Developing countries do not pay enough attention to the clients with endocrinal disorder regarding their symptoms, laboratory test, the challenges they face throughout the life in different aspect of life thus resulting increased morbidity and mortality rate [1]. The profile of endocrine disorders differs in developing countries like India when compared with the developed world as very small number of population-based reports are available regarding endocrine diseases from India [1].

There are some worldwide study regarding different problems faced by the clients with specific types of endocrinal disorders like Diabetes, Thyroid, Pituitary, Adrenal, and Parathyroid disorder separately but there are no published study regarding the common challenges faced by the clients with endocrinal disorder even in India. From the clinical experience the researcher found as all the endocrinal disorders cause hormonal imbalance in the body and it is a chronic problem of all the adult clients with endocrinal disorder. They face some general challenges or problems in their different stages of life in many aspects like physical, psychological, personal, social and obviously in financial domain because of the long-term necessity of medication and the follow up treatment which are sometimes overlooked. Due to the chronic suffering and different alteration of health those clients need support from family and social support too. With this intension researcher is chosen this study.

\section{Subjects \& Methods}

To achieve the study objectives of the study a non-experimental descriptive survey research was conducted between October and November, 2019 at Endocrine OPD of a selected Medical College and Hospital, Kolkata. Data collected from 170 adult clients through purposive sampling technique and ethical clearance have obtained from Institutional Ethics Committee and informed consent was taken from the client. Samples were being selected by excluding clients with endocrinal disorder who were suffering for less than one year and who were diagnosed as endocrine disorder associated with psychiatric illness, any other chronic disorder such as heart disease, lung disease, and carcinoma, neurological disorder, chronic liver diseases. Researcher collected demographic data by administering structured interview schedule and data regarding challenges they face and the support system they receive both by administering semi-structured interview schedule. Validity \& reliability of the tool was established before final data collection. SPSS Statistics version 17 (2008, SPSC Inc, Chicago, Illinois, USA) software is used for statistical analysis. Frequency and percentage distribution is computed for describing the demographic characteristics, challenges faced in different domain and the support system. Mean, Mean percentage, Rank is computed for domain of challenges and Chi Square test is calculated to find out the association between challenges with demographical variables. Mild, Moderate and Severe level of challenges have been calculated by the formula: Mild=< Mean $-1 \mathrm{SD}$, Moderate $=$ Mean $\pm 1 \mathrm{SD}$, Severe $=>$ Mean $+1 \mathrm{SD}$. For support level, it is categorize as poor support system (below 33\%), average support system (33\%-66\%), and Good support system (above 66\%).

\section{Results}

Data presented in Table 1A shows that majority (67\%) of clients with endocrinal disorder are female. Forty percent (40\%) of them are from $42-53$ years among them $61 \%$ client's education level is primary and secondary level. Forty seven percent (47\%) clients are homemakers. Data presented in Table 1B shows that 37\% clients are suffering from the illness from 5 years to 10 years. Fifty three percent (53\%) clients are having diabetes mellitus, $44 \%$ thyroid disorder and 3\% pituitary disorder. Table 2 depicts that psychological domain scores with a mean of 16.38 and mean percentage $68.25 \%$ which ranked as 1 st. The social domain scores with a mean of 7.47 and mean percentage $37.38 \%$ which ranked as $5^{\text {th }}$. 
Table 1A. Frequency and percentage distribution of selected socio-demographic variables $(\mathbf{N}=170)$

\begin{tabular}{|c|c|c|c|}
\hline SI No. & Demographic variables & Frequency & Percentage \\
\hline 1. & $\begin{array}{l}\text { Gender } \\
\text { Male } \\
\text { Female }\end{array}$ & $\begin{array}{c}56 \\
114\end{array}$ & $\begin{array}{l}33 \% \\
67 \%\end{array}$ \\
\hline 2. & $\begin{array}{l}\text { Age } \\
\text { 18-29 yrs. } \\
\text { 30-41 yrs. } \\
42-53 \text { yrs. } \\
54-65 \text { yrs. }\end{array}$ & $\begin{array}{l}12 \\
37 \\
68 \\
53\end{array}$ & $\begin{array}{l}7 \% \\
22 \% \\
40 \% \\
31 \%\end{array}$ \\
\hline 3. & $\begin{array}{c}\text { Marital status } \\
\text { Married } \\
\text { Unmarried } \\
\text { Widow/Separated }\end{array}$ & $\begin{array}{c}152 \\
5 \\
13\end{array}$ & $\begin{array}{l}89 \% \\
3 \% \\
8 \%\end{array}$ \\
\hline 4. & $\begin{array}{c}\text { Educational status } \\
\text { Illiterate } \\
\text { Primary and Secondary } \\
\text { Higher Secondary and above }\end{array}$ & $\begin{array}{c}49 \\
103 \\
18\end{array}$ & $\begin{array}{l}29 \% \\
61 \% \\
10 \%\end{array}$ \\
\hline 5. & $\begin{array}{l}\text { Occupation } \\
\text { Employed } \\
\text { Homemakers } \\
\text { Others }\end{array}$ & $\begin{array}{l}71 \\
80 \\
19\end{array}$ & $\begin{array}{l}42 \% \\
47 \% \\
11 \%\end{array}$ \\
\hline 6. & $\begin{array}{c}\text { No. of family members } \\
\leq 4 \\
5-10 \\
>10\end{array}$ & $\begin{array}{c}112 \\
52 \\
6\end{array}$ & $\begin{array}{c}66 \% \\
31 \% \\
3 \%\end{array}$ \\
\hline
\end{tabular}

Table 1B. Frequency and percentage distribution of disease related characteristics of the subject $(\mathrm{N}=170)$

\begin{tabular}{cccc}
\hline Sl No. & Disease related variables & Frequency & Percentage \\
\hline Duration of suffering & & \\
$1-5$ yrs. & 60 & $35 \%$ \\
1.10 yrs. & 63 & $37 \%$ \\
& $>10$ yrs. & 47 & \\
& & \\
& Types of endocrinal disorder & & \\
& Diabetes Mellitus (n1) & 90 & $53 \%$ \\
Thyroid disorder (n2) & 74 & $3 \%$ \\
& Pituitary disorder (n3) & 6 & \\
\hline
\end{tabular}

Table 2. Domain wise Range, Mean, Mean percentage and Rank of challenges faced by clients with endocrinal disorder in terms of total score of challenges $\left[N\left(n_{1}+n_{2}+n_{3}\right)=170\right]$

\begin{tabular}{cccccc}
\hline SI No. & Challenges & Range & Mean & MeanPercentage & Rank \\
\hline 1. & Psychological challenges & $4-24$ & 16.382 & $68.25 \%$ & 1st \\
2. & Financial challenges & $2-8$ & 5.329 & $66.61 \%$ & 2nd \\
3. & Personal challenges & $2-20$ & 13.276 & $66.38 \%$ & $3 r d$ \\
4. & Physical challenges & $4-24$ & 15.494 & $64.55 \%$ & 4 th \\
5. & Social challenges & $0-20$ & 7.476 & $37.38 \%$ & 5th \\
\hline
\end{tabular}

Data presented in Figure 1 reflect that 97\% and 74\% clients with thyroid disorder are having energy loss and hair fall problems respectively which are comparatively more than the clients with diabetes mellitus and pituitary disorder whereas sleeplessness is more among clients with pituitary disorder which is $83 \%$ and fatigability is more 
among clients with diabetes mellitus and thyroid disorder than clients with pituitary disorder that are 96\%, 99\% and 83\% respectively. All (100\%) the clients with pituitary disorder face the challenges of weight changes. Regarding weight changes $37 \%$ face weight gain and $55 \%$ face weight loss. In physical challenges, regarding bowel elimination disorder $50 \%$ faced constipation and $21 \%$ faced diarrhea. From Figure 2, we can see that anxiety is present in $100 \%$ clients with thyroid and pituitary disorder both and the $98 \%$ clients with diabetes mellitus. All (100\%) the clients feel hopelessness and 100\% clients with pituitary disorder reported of lack of concentration and 100\% clients with pituitary disorders have challenges in memory loss, lack of patience and fearfulness regarding disease progress. A study result also shows that the $94 \%$ client with diabetes, $99 \%$ client with thyroid and $100 \%$ client with pituitary disorder blame themselves for their disease for lifelong (Figure 3). Diet restriction is more (99\%) in clients with diabetes and all (100\%) the clients with thyroid and pituitary disorder face the problems for body image disturbances (Figure 3).

Figure 4 reflects that in social domain, blaming by family members are more in the clients with pituitary disorder which is $83 \%$, hundred percent (100\%) clients with pituitary disorder do not feel for any social interest. All (100\%) the clients with thyroid and pituitary disorder face problems for bearing the medicine expenses and all the clients have challenges for the other treatment expenses such as travelling, diagnostic procedures, outside lodging needed for treatment (Figure 5).

Data presented in Figure 6 reflect that $64 \%$ of clients with diabetes and thyroid disorder both are moderately challenged whereas $66 \%$ of clients with pituitary disorder are moderately challenged and $22 \%$ clients with diabetes, $13 \%$ clients with thyroid and $17 \%$ clients with pituitary disorder are severely challenged respectively.

From Figure 7A and Figure 7B, we can see that clients get family support in terms of taking care of personal hygiene, helping in maintaining diet, helping in administration of medication and giving reminder for medication from family $88 \%, 78 \%, 69 \%$ and $96 \%$ respectively whereas the social support in these aspects are comparatively very less which are $4 \%, 1 \%, 0 \%$ and $14 \%$ respectively. Figure 8 depicts that in terms of total support the $62 \%$ clients get good family support and $10 \%$ clients get poor family support but maximum clients (99\%) get poor social support. The study result also reflects that $2 \%$ clients don't have any primary support person and for $68 \%$ client the primary support person is their spouse (Figure 9).

Table 3A reflects that maximum (91\%) clients have the opinion to improve the financial support from their spouse and adult children and $87 \%$ clients have the opinion to increase the psychological support from their primary support person such as adult children, daughter in law and spouse. Only 58\% clients with endocrinal disorder are satisfied with the primary support person (Table 3B).

Data presented in Table 4A depicts that there is a significant association between challenges faced by clients with endocrinal disorder and their selected socio-demographic variables like gender, age, marital status, education, occupation, number of family member. Table $4 \mathrm{~B}$ reflects that there is a significant association between challenges faced by client with endocrinal disorder and their disease related characteristics like duration of suffering and types of endocrinal disorder.

\section{$\square$ Diabetes Mellitus $\quad$ Thyroid Disorder $\quad$ Pituitary disorder}

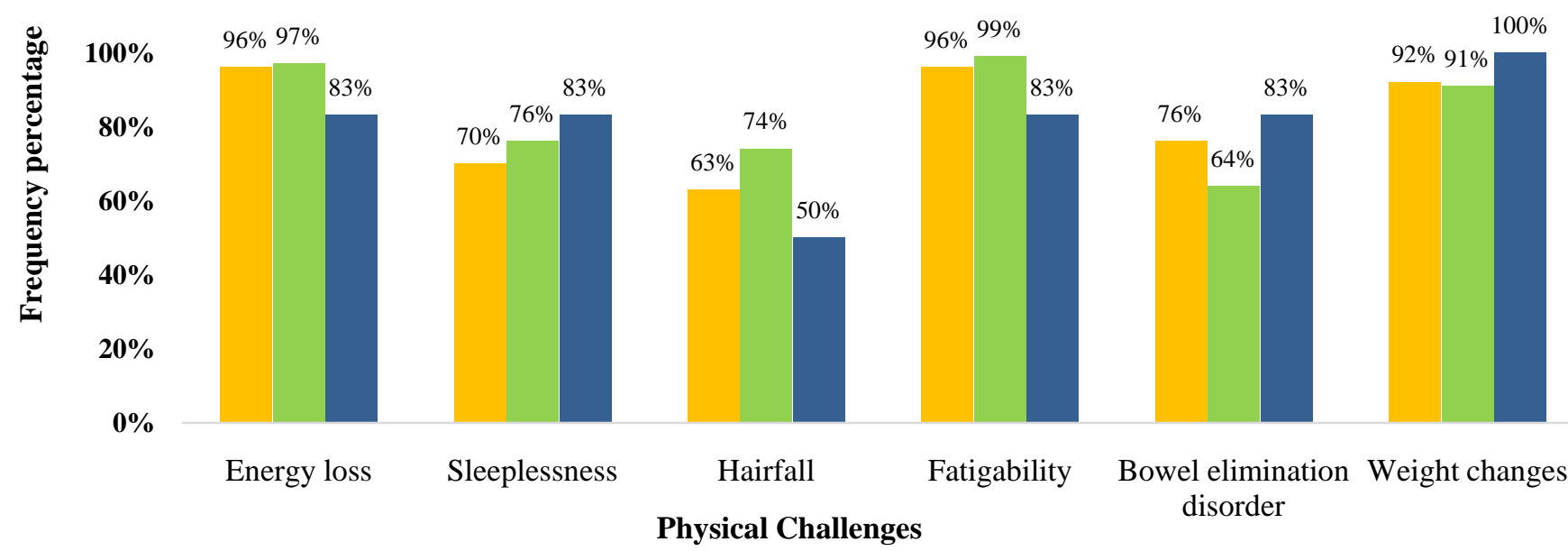

Figure 1. Comparative bar diagram showing percentage distribution of Physical Challenges $\left[N\left(\mathbf{n}_{1}+\mathbf{n}_{2}+\mathbf{n}_{3}\right)=170\right]$. 


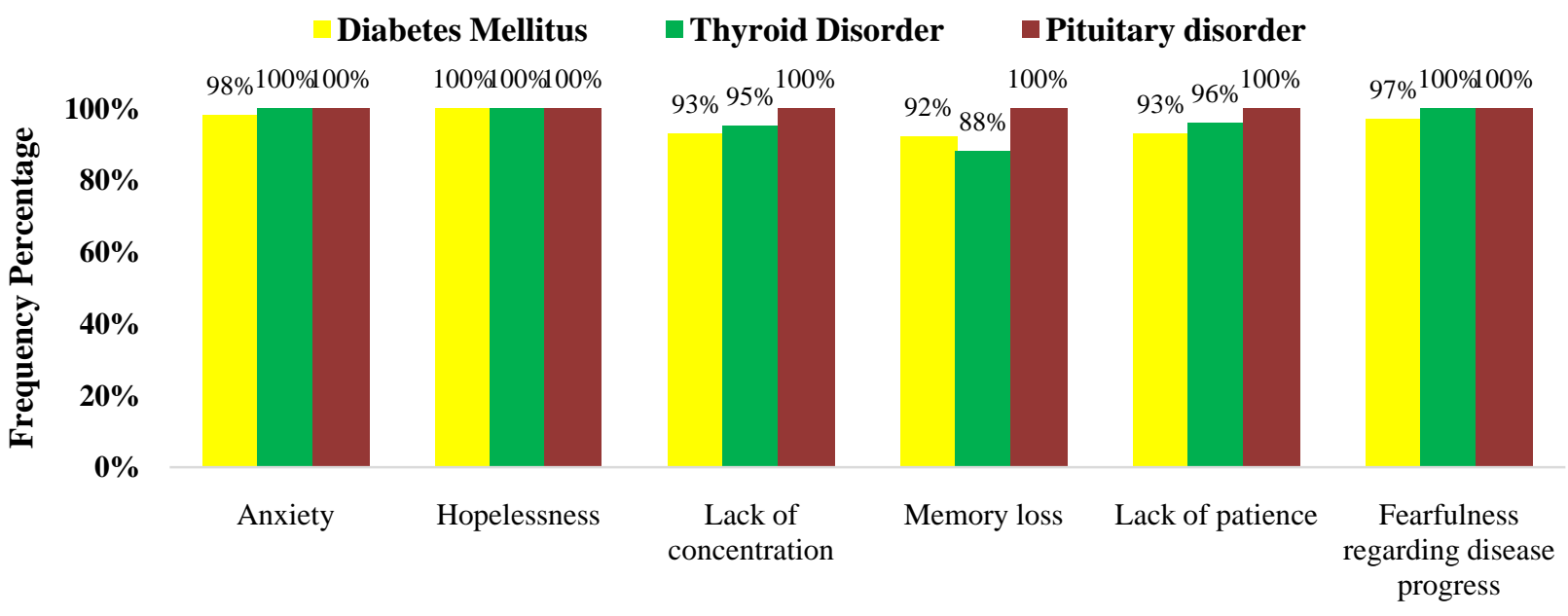

Psychological Challenges

Figure 2. Comparative bar diagram showing percentage distribution of Psychological Challenges $\left[N\left(n_{1}+n_{2}+n_{3}\right)=170\right]$.

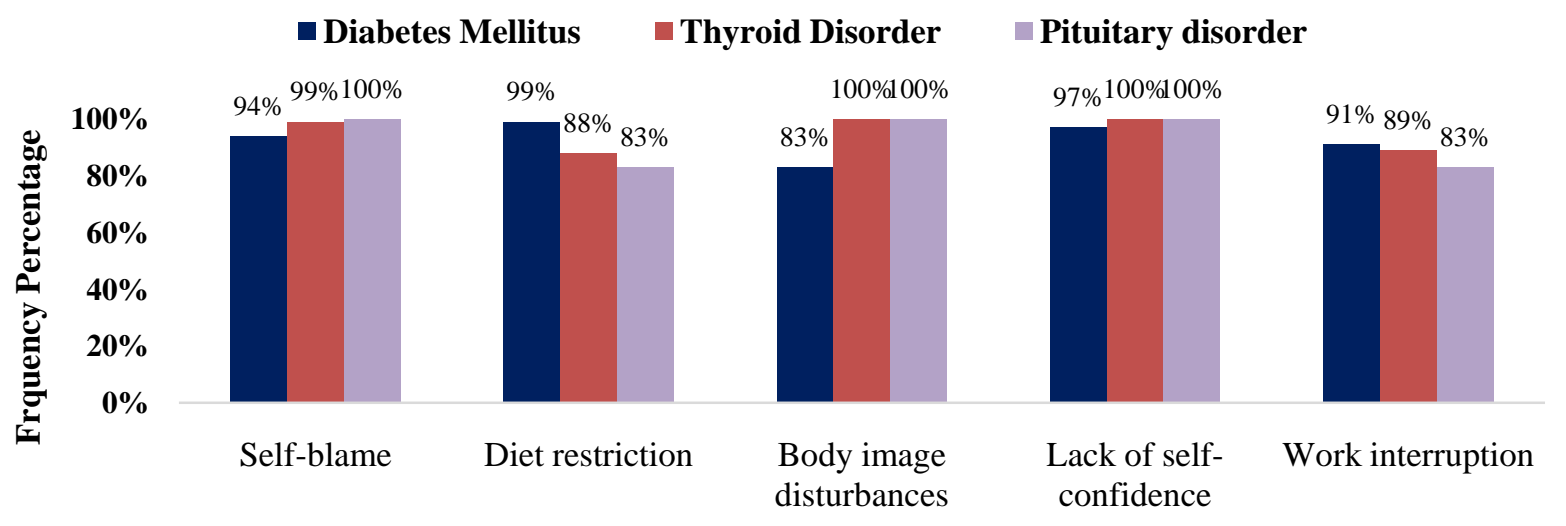

Personal Challenges

Figure 3. Comparative bar diagram showing percentage distribution of Personal Challenges $\left[N\left(n_{1}+n_{2}+n_{3}\right)=170\right]$.

Diabetes Mellitus $\quad$ Thyroid Disorder $\quad$ Pituitary disorder

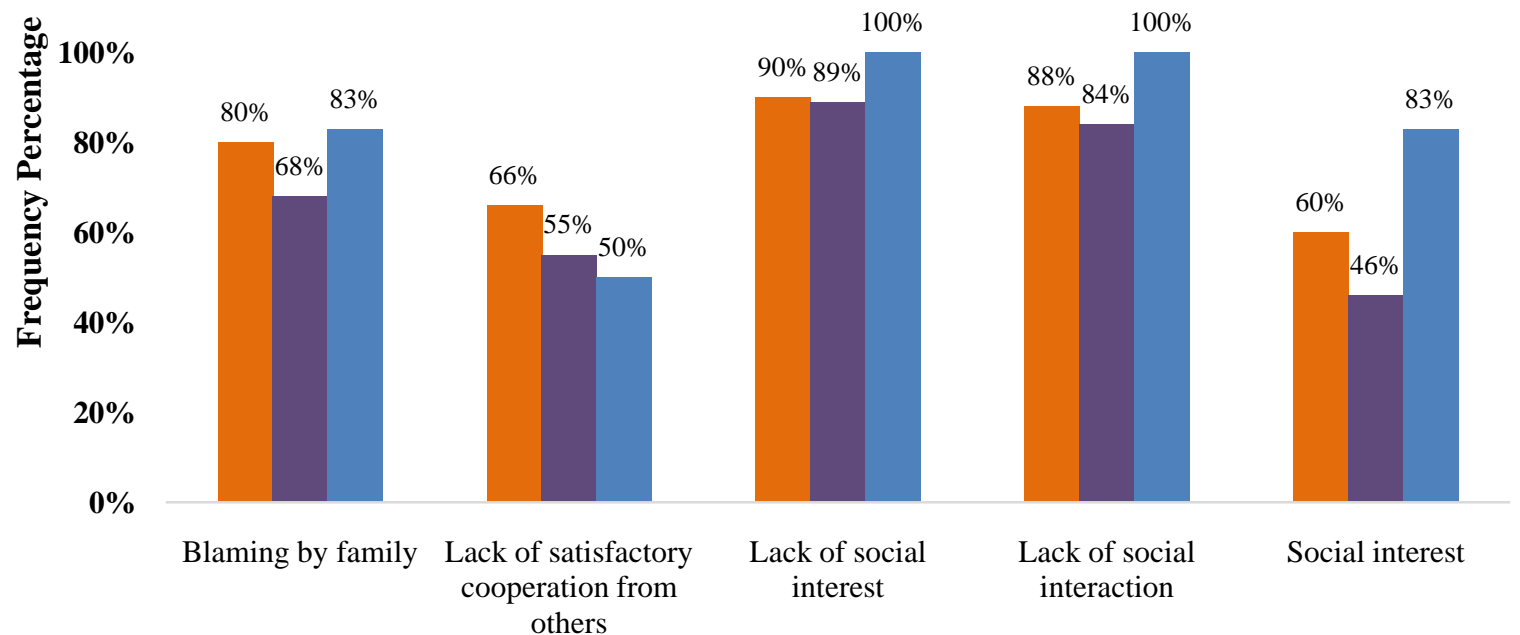

Social Challenges

Figure 4. Comparative bar diagram showing percentage distribution of Social Challenges $\left[N\left(n_{1}+n_{2}+n_{3}\right)=170\right]$. 
- Diabetes Mellitus

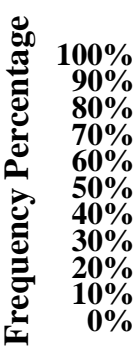

\section{Thyroid Disorder}

$97 \% 100 \% 100 \%$

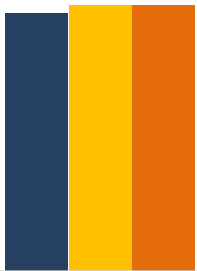

\section{Pituitary disorder}

$100 \% 100 \% 100 \%$

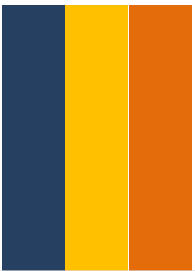

Difficulty to bear medicine expenses Financial problem for other treatment expenses

\section{Financial Challenges}

Figure 5. Comparative bar diagram showing percentage distribution of Financial Challenges $\left[N\left(\mathbf{n}_{1}+\mathbf{n}_{2}+\mathbf{n}_{3}\right)=170\right]$.

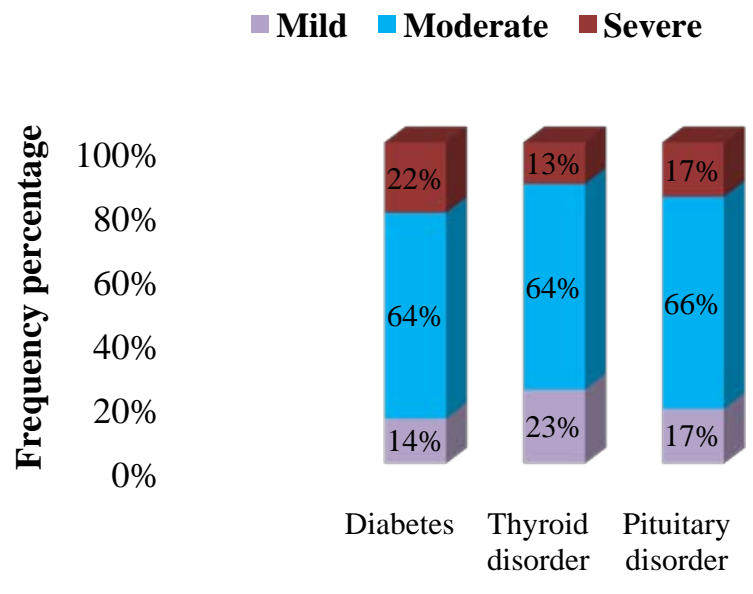

Frequency of level of challenges

Figure 6. Comparative proportional bar (3D column) diagram showing percentage distribution of level of challenges of clients with endocrinal disorder $\left[N\left(n_{1}+n_{2}+n_{3}\right)=170\right]$.

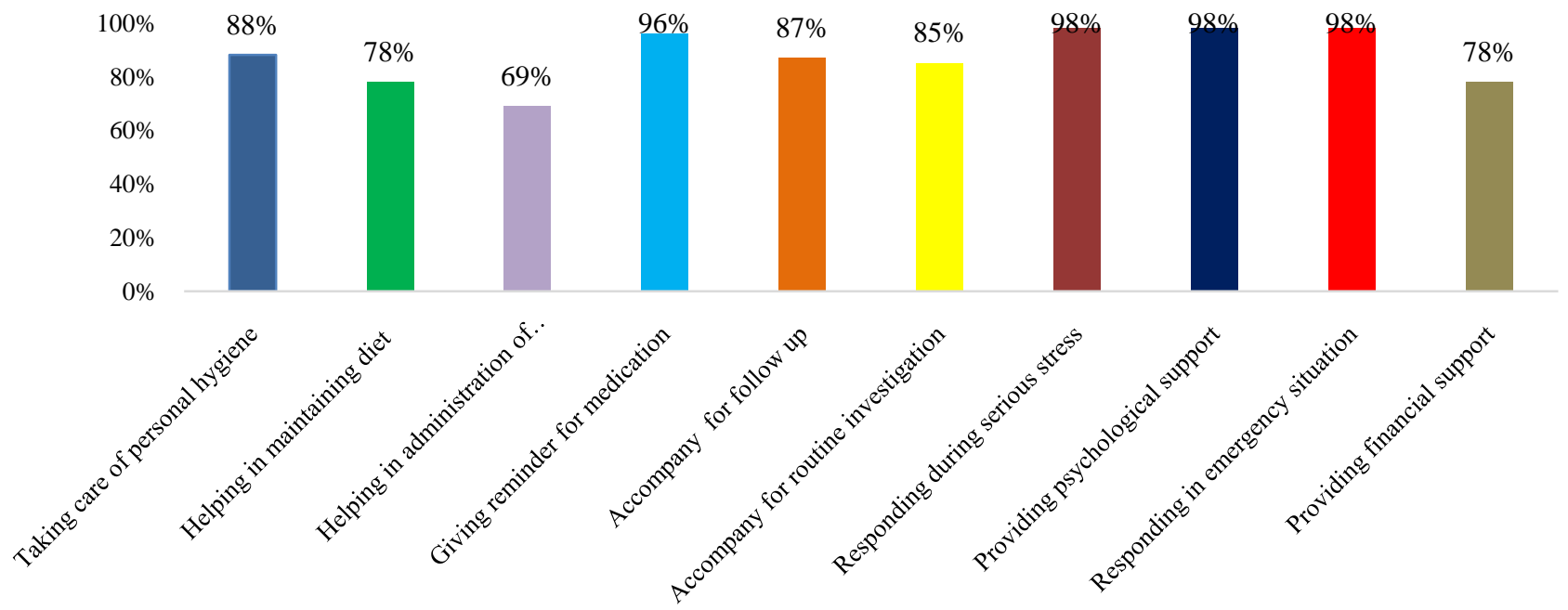

Figure 7A. Bardiagram showing percentage distribution of Family support of the clients having endocrinal disorder (Frequency percentage not mutually exclusive) $\left[N\left(n_{1}+n_{2}+n_{3}\right)=170\right]$. 


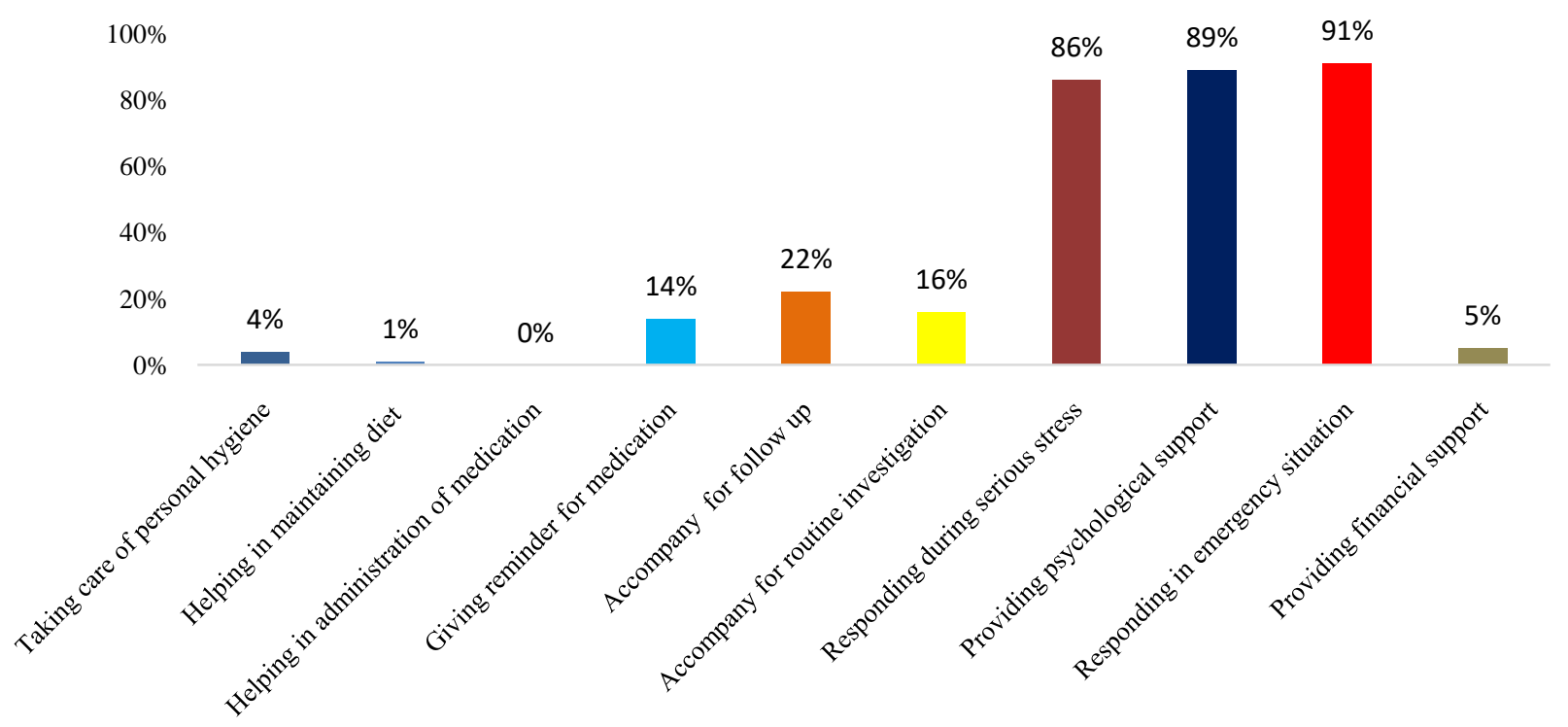

Figure 7B. Comparative bar diagram showing percentage distribution of support from Neighbors/Friends/Relatives of the clients having endocrinal disorder (Frequency percentage not mutually exclusive) [N $\left.\left(\mathbf{n}_{1}+\mathbf{n}_{2}+\mathbf{n}_{3}\right)=170\right]$.

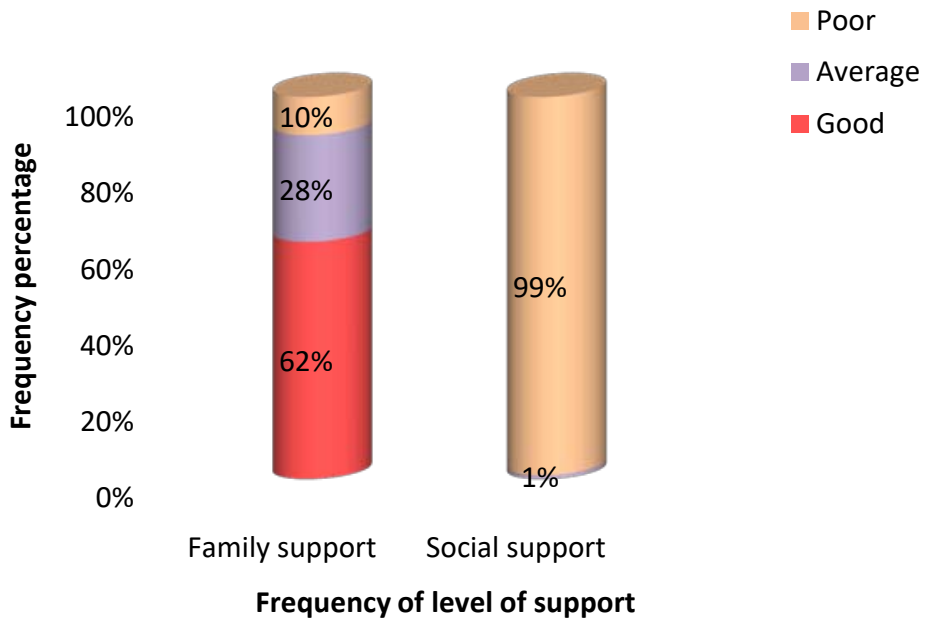

Figure 8. Comparative proportional bar (3D cylindrical) diagram shows percentage distribution of level of support received by clients with endocrinal disorder.

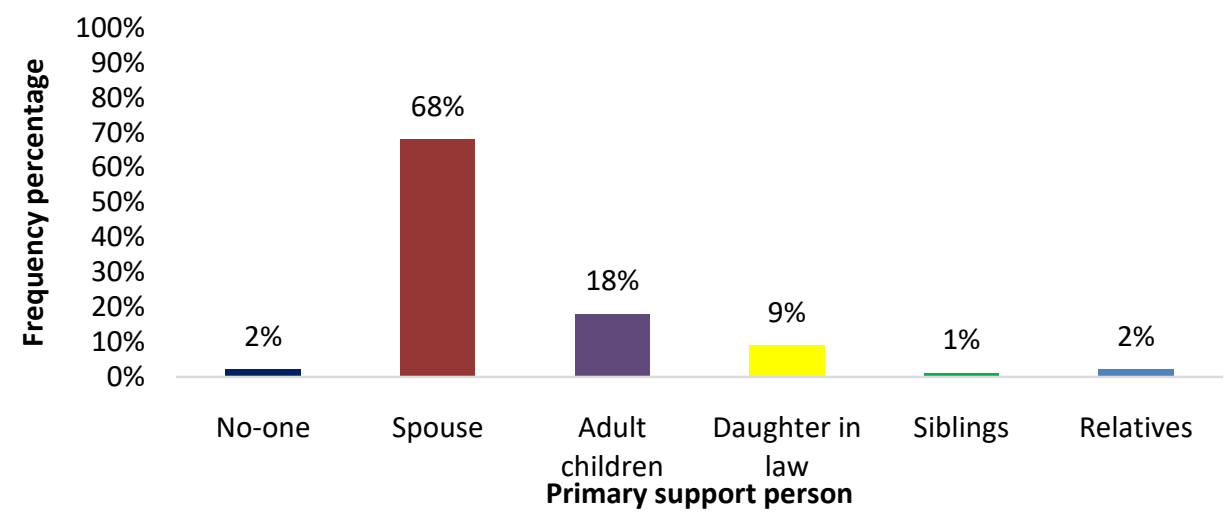

Figure 9. Bar diagram shows percentage distribution of primary support person of the clients with endocrinal disorder. 
Table 3A. Frequency and percentage distribution of level of satisfaction of support received by clients with endocrinal disorder from their primary support person $\left[N\left(\mathbf{n}_{1}+\mathbf{n}_{2}+\mathbf{n}_{3}\right)=170\right]$

\begin{tabular}{cccc}
\hline Opinion related to satisfaction & Frequency & Percentage \\
\hline & No opinion & 17 & $10 \%$ \\
$\bullet$ & Satisfied & 98 & $58 \%$ \\
$\bullet$ & Not satisfied & 55 & $32 \%$ \\
\hline
\end{tabular}

Table 3B. Frequency and percentage distribution of opinion of the clients with endocrinal disorder regarding improvement of the support from their primary support person $\left[N\left(\mathbf{n}_{1}+\mathbf{n}_{2}+\mathbf{n}_{3}\right)=55\right]$

\begin{tabular}{|c|c|c|}
\hline Opinion related to improvement of support & Frequency & Percentage \\
\hline - $\quad$ More psychological support & 48 & $87 \%$ \\
\hline - $\quad$ More financial support & 50 & $91 \%$ \\
\hline - $\quad$ Accompany for follow up & 20 & $36 \%$ \\
\hline - Helping for maintaining the proper diet & 25 & $45 \%$ \\
\hline
\end{tabular}

Table 4A. Association between challenges with the selected socio demographical variables $\left[N\left(n_{1}+n_{2}+n_{3}\right)=170\right]$

\begin{tabular}{|c|c|c|c|c|c|}
\hline Sl no. & $\begin{array}{l}\text { Selected So- } \\
\text { cio-demograph } \\
\text { ic variables }\end{array}$ & $\begin{array}{c}\text { Below Median } \\
\text { No. }\end{array}$ & $\begin{array}{l}\text { At and Above } \\
\text { Median No. }\end{array}$ & $\begin{array}{c}\text { Chi Square } \\
\text { value }\end{array}$ & $P$ value \\
\hline 1. & $\begin{array}{lc} & \text { Gender } \\
\text { - } & \text { Male } \\
\text { - } & \text { Female }\end{array}$ & $\begin{array}{l}45 \\
42\end{array}$ & $\begin{array}{l}11 \\
72\end{array}$ & 28.459 & $<0.00001$ \\
\hline 2. & $\begin{array}{ll} & \text { Age } \\
\text { - } & 18-29 \text { yrs. } \\
\text { - } & 30-41 \text { yrs. } \\
\text { - } & 42-53 \text { yrs. } \\
\text { - } & 54-65 \text { yrs. }\end{array}$ & $\begin{array}{c}8 \\
20 \\
24 \\
32\end{array}$ & $\begin{array}{c}4 \\
17 \\
44 \\
21\end{array}$ & 9.719 & 0.021 \\
\hline 3. & $\begin{array}{lc}\text { Marital Status } \\
\bullet \quad \text { Married } \\
\text { - } \quad \text { Unmar- } \\
\text { ried } \\
\text { /Widow/ } \\
\text { Separated }\end{array}$ & $\begin{array}{c}80 \\
5\end{array}$ & $\begin{array}{l}72 \\
13\end{array}$ & 3.976 & 0.046 \\
\hline 4. & $\begin{array}{l}\text { Education } \\
-\quad \text { Illiterate } \\
\text { - } \quad \text { Primary } \\
\text { and secondary } \\
\text { • } \quad \text { Higher } \\
\text { secondary and } \\
\quad \text { above }\end{array}$ & $\begin{array}{l}14 \\
58 \\
17\end{array}$ & $\begin{array}{l}35 \\
45 \\
1\end{array}$ & 24.540 & $<0.00001$ \\
\hline 5. & $\begin{array}{c}\text { Occupation } \\
\text { - } \quad \text { Employed } \\
\text { Home- } \\
\text { makers } \\
\text { - } \quad \text { Others } \\
\text { Number of } \\
\text { Family Member }\end{array}$ & $\begin{array}{l}42 \\
30 \\
16\end{array}$ & $\begin{array}{c}29 \\
50 \\
3\end{array}$ & 16.083 & 0.000 \\
\hline 6. & $\begin{array}{cc}- & \leq 4 \\
- & 5-10 \\
- & >10\end{array}$ & $\begin{array}{c}69 \\
20 \\
3\end{array}$ & $\begin{array}{c}43 \\
32 \\
3\end{array}$ & 7.704 & 0.021 \\
\hline
\end{tabular}


Table 4B. Association between challenges with the selected disease related characteristics $\left[N\left(n_{1}+n_{2}+n_{3}\right)=170\right]$

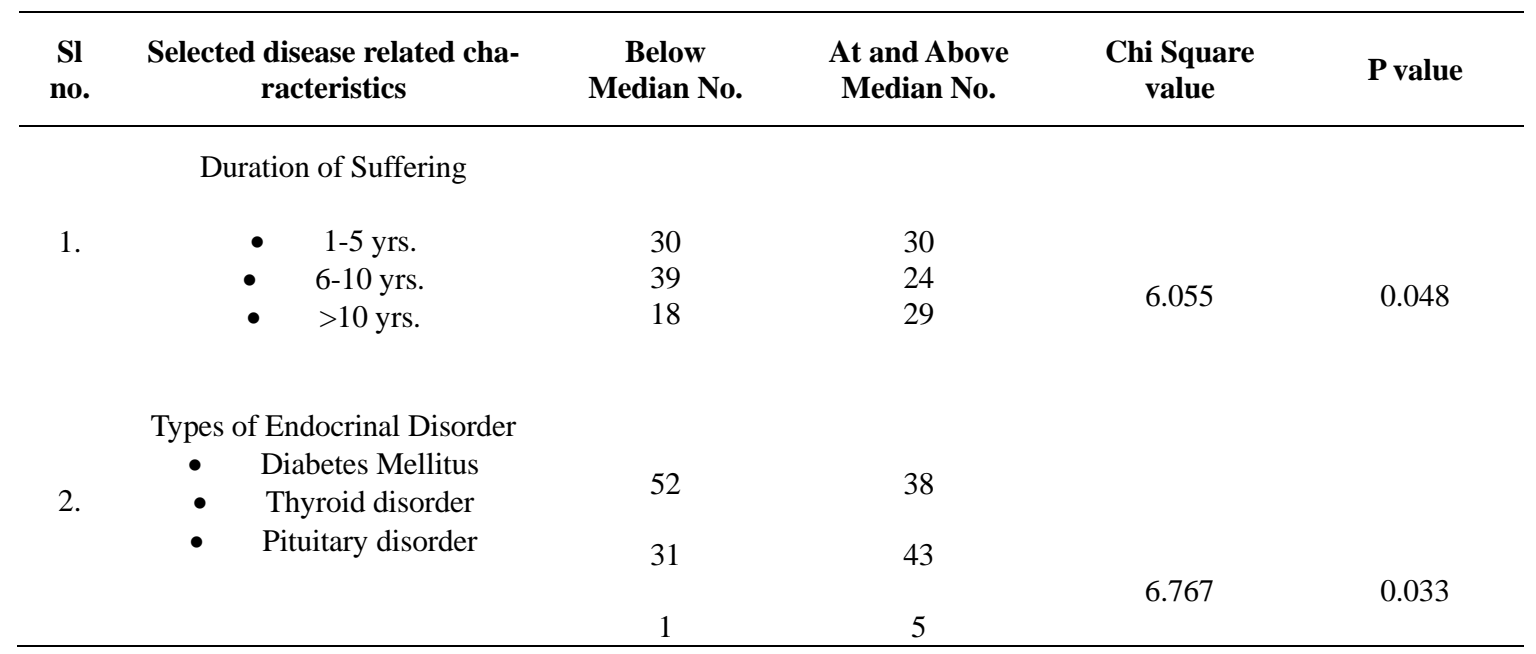

\section{Discussion}

In the present study, it has been found that psychological challenges of clients with endocrinal disorder ranked first $\left(1^{\text {st }}\right)$ among all the domains and specially all the client with endocrinal disorder are having challenges in terms of hopelessness for the chronic disease condition, clients with pituitary disorder have more lack of concentration than clients with diabetes and thyroid disorder. All the clients with pituitary disorder also have challenges in terms of memory loss, lack of patience and fearfulness. It is also found that $98 \%$ clients with diabetes and $100 \%$ clients with pituitary disorder have anxiety due to the suffering. This finding corresponds to the study findings by Kalra, Jena, Yaravdekar [3] and they found that anxiety is common psychological disorder in patients with diabetes. The systematic review of A. B. Grigsby, R. J. Anderson, K. E. Freedland et al. [9] also supports this findings. They reported higher prevalence of anxiety in diabetes patients with $14 \%$ of clients who were suffering from generalized anxiety disorder, $27 \%$ with sub-syndromal anxiety disorder, and $40 \%$ with elevated anxiety symptoms than those without diabetes. Brod, Pohlman, LHøjbjerre et al. [10] also found in their studies that clients with adult growth hormone deficiency (AGHD) reported a wide range of the emotional impacts including frustration, anxiety, anger, mood swings as a result of AGHD. The researcher found in recent study that financial challenges of clients with endocrinal disorder ranked second $\left(2^{\text {nd }}\right)$ among all the domains. All the clients with thyroid and pituitary disorders face problems for medicine expenses because they are having financial burden to buy the medication for lifelong and they do not get the medicine at free of cost from the hospital whereas the $97 \%$ clients with diabetes have this challenge. Though the clients with diabetes get few medications at free of cost but sometimes for inadequate supply of all types of diabetes medications, they face this problem. All the clients with endocrinal disorder have challenges in the other treatment expenses such as repeated travelling for follow up and investigation, investigation from the others private diagnostic center (due to delaying appointment in govt. hospital) and for outside lodging in any emergency or long distance. The study of Campbell, Manns, Hemmelgarnetal [11] supports these findings and they reported that clients with type 1 or type 2 diabetes have financial barriers on medications, diabetes supplies, and healthy food. The result of present study also reveals that there is significant association between challenges and the socio-demographic variable gender which show male clients who have less challenges than females. These findings are consistent with the findings of the study conducted by Siddiqui, Khan, and Carine [12] in 2013 on Gender Differences in Living with Diabetes Mellitus in which the male diabetic clients were observed to be living more effectively with diabetes, lesser depression and anxiety but more energy and better positive wellbeing. The study of Bathla, Singh, and Relan [13] also supports the findings, they found that the most common anxiety symptom in males was the depressing mood (70.0\%) and among females was the anxious mood (92.85\%). In support system, the study of fact revealed that the $98 \%$ and $89 \%$ clients received psychological support from family members and social members respectively which is quite satisfactory and they get response during serious stress from them too, which is very necessary for those clients with the chronic disorders. According to the study of Miller, T. A. and DiMatteo, M. R. [14] on importance of family/social support and impact on adherence to diabetic therapy, they reported that the social support from family provides patients with practical help and it can easily buffer the stresses of living with illness. Specially, they found patient adherence and "living with others" is very stronger for behavioral regimens compared with medication regimens and he also finds the practical and emotional support has 
stronger effects on adherence than do structural social support.

In this study, it is found that the $78 \%$ clients with endocrinal disorder get financial support from their family members and the family members accompany for follow up and routine investigation for $87 \%$ and $85 \%$ clients respectively and $78 \%$ clients get help from family members in maintaining diet. Pesantes, M. A. et al. [15] supported those findings, they found that clients with T2DM receive financial assistance from their children and the money is mostly to pay for bills and medications, and their family members are always by his side during medical appointments, and their family members would tell participants to be mindful about what they consume, while also preparing healthy foods for them.

It is expected from the nursing fraternity that they should teach the nursing student regarding holistic care of a client mainly those persons are suffer from chronic diseases like endocrinal disorder. This study has limitation too that is it is limited to the clients with diabetes, thyroid and pituitary disorder only because researcher did not get clients with others endocrinal disorder during the data collection period.

\section{Conclusion}

The present study reveals that due to chronic suffering of the clients with endocrinal disorder are getting more challenges in psychological domain. All the clients have some challenges in each domain. Clients with pituitary disorder are getting comparatively more challenges than diabetes and thyroid disorder. They are receiving support from their family and social members but social support is very less and poor for them. Hence identifying the challenges of those clients and support system will provide some information which will help them in counseling so that they can overcome the challenges themselves and can lead a better life.

\section{Acknowledgment}

We are grateful to the Principal \& MSVP of selected hospital, Kolkata for providing permission and support to carry out this work. The authors also acknowledge the cooperation of the patients who participated in the study.

\section{References}

[1] Sarfo-Kantanka, O., Sarfo, F. S., Ansah, E. O., Kyei, I. (2017). Spectrum of Endocrine Disorders in Central Ghana. Int J Endocrinol., 2017: 5470731. Doi: 10.1155/2017/5470731.

[2] Kaveeshwar, S. A., Cornwall, J. (2014). The Current State of Diabetes Mellitus in India. Australas Med J., 7(1): 45-48.

[3] Kalra, S., Jena, B. N., Yeravdekar, R. (2018). Emotional and Psychological Needs of People with Diabetes. Indian J Endocrinol Metab., 22(5): 696-704.

[4] Kochupillai, N. (2000). Clinical endocrinology in India. Curr Sci., 79: 1061-7.

[5] Trief, P. M., Sandberg, J. G., Dimmock, J. A., Forken, P. J., Weinstock, R. S. (2013). Personal and Relationship Challenges of Adults With Type 1 Diabetes. Diabetes Care. American Diabetic Association, 36(9): 2483-2488.

[6] Jha, S., Jayaraman, M., Jha, A., Jha, R., Modi, K. D., Kelwadee, J. V. (2016). Primary hyperparathyroidism: A changing scenario in India. Indian Journal of Endocrinology and Metabolism, 20(1): 80.

[7] Walker, M. D., Rubin, M., Silverberg, S. J. (2013). Nontraditional manifestations of primary hyperparathyroidism. Journal of Clinical Densitometry, 16(1): 40-7.

[8] Brody, E. Jane. (2017). The Subtle Signs of a Thyroid Disorder. Personal Health. The New York Times. July 24, 2017; Section D: Page 5. Available from https://www.nytimes.com/2017/07/24/well/live/the-subtle-signs-of-a-thyroid-disorder.html.

[9] Grigsby, A. B., Anderson, R. J., Freedland, K. E., Clouse, R. E., Lustman, P. J. (2002). Prevalence of anxiety in adults with diabetes: a systematic review. Journal of Psychosomatic Research, 2002 Dec., 53(6): 1053-60.

[10] Brod, M., Pohlman, B., Højbjerre, L., Adalsteinsson, J. E., Rasmussen, M. H. (2014). Impact of adult growth hormone deficiency on daily functioning and well-being. BMC Res Notes. 2014 Nov 18; 7: 813. doi: 10.1186/1756-0500-7-813.

[11] Campbell, D. J., Manns, B. J., Hemmelgarn, B. R., Sanmartin, C., Edwards, A., King Shier, K. (2017). Understanding financial barriers to care in patients with diabetes. Diabetes Educ., 43(1): 78-86.

[12] Siddiqui, M. A., Khan, M. F., Carline, T. E. (2013). Gender differences in living with diabetes mellitus. Mater Sociomed., 25(2): 140-142. doi: 10.5455/msm.2013.25.140-142.

[13] Bathla, M., Singh, M., Relan, P. (2016). Prevalence of anxiety and depressive symptoms among patients with hypothyroidism. Indian J Endocrinol Metab., 2016 Jul-Aug; 20(4): 468-74. doi: 10.4103/2230-8210.183476.

[14] Miller, T. A., Dimatteo, M. R. (2013). Importance of family/social support and impact on adherence to diabetic therapy. Diabetes Metab Syndr Obes., 2013 Nov 6; 6: 421-6.

[15] Pesantes, M. A., Del Valle, A., Diez-Canseco, F., Bernabé-Ortiz, A., Portocarrero, J., Trujillo, A., et al. (2018). Family support and diabetes: Patient's experiences from a public hospital in Peru. Qual Health Res., 2018 Oct; 28(12): 1871-1882. 